\title{
Developing CALL to Meet the Needs of Language \\ Teaching and Learning
}

\author{
Zhaofeng Jiang \\ College English Department \\ Guangxi Teachers Education University \\ 175 Mingxiu Road, Nanning 530001, China \\ E-mail: mariajiang@gmail.com
}

\begin{abstract}
This paper illustrates the advantages and disadvantages of CALL. It points out that CALL is influenced by traditional language teaching and learning approaches to some extent .It concludes that what is important in our university system is that CALL design and implementation should match the users' needs, since CALL is not always better than traditional language learning and teaching method.
\end{abstract}

Keywords: CALL, Traditional language learning and teaching, L2

\section{Introduction}

CALL stands for the acronym of Computer Assisted Language Learning. Levy (1997) defines CALL as "the search for and study of applications of the computer in language teaching and learning". With the dramatic development of information technology, computers are widely used in various areas including language teaching and learning area. Much research has been done on the application of computers in language learning and teaching. Both traditional language learning and CALL have advantages and disadvantages. CALL is influenced by traditional language teaching and learning approaches to some extent. Although language teaching and learning approaches are different, but the goal is the same: to develop the learners' abilities as the same as native speakers. The aim of developing CALL is not to provide language with novelty, but is to improve the quality of language teaching (Cameron, 1989).it is important in colleges and university that CALL design and implementation should meet the needs of L2 learners. because there is so much research involved in this area, we would describe CALL as a field in which it is difficult to become an expert. It requires a lot of knowledge from many different disciplines and areas, but I find that this makes the field itself more interesting, since there is always something different to investigate and research.

\section{CALL and Traditional Language Learning}

Language learning and teaching is a two-way communication. Traditionally, it needs fixed places and large amounts of papers and chalks. Traditional language teaching and learning is teacher centered, it is not flexible and students don't have their own autonomy. Large numbers of students are crowded in a classroom and black or white board make teachers busy although overhead projector makes things a little better.

For teaching and learning speaking and listening, Audiolingual method is the best choice, but for reading and writing, cognitive code and communicative are the priorities. But when developing a CALL system, things should be more flexible. I think CALL is not simply an open approach, neither a simple traditional closed approach. CALL should be more flexible to its learners, and it should be a mixture of closed and open approaches since it is a no-boundary classroom and the learners are different. CALL now includes highly interactive and communicative support for listening, speaking, reading and writing, including extensive use of multimedia CD-ROMs and the Internet.

\subsection{Advantages and disadvantages of CALL}

CALL makes language learning and teaching flexible. Active videos, colourful pictures and graphs make learners exciting and not bored of it. But there are some constraints on the practice of CALL as well, such as learners' lack of technical competence, poor interaction among learners, etc. Table 1 shows some advantages and disadvantages of CALL. 
There seems little doubt that CALL is presently the most innovative area in the practice of foreign or second language teaching and learning.

\subsection{Differences between traditional language learning and CALL}

Traditional language learning and teaching is also called classroom teaching. Knowledge about classroom language learning and teaching probably does not apply directly to CALL because of the different configuration of variables such as learners' and teachers' roles, location, and interactivity. As Figure 1 illustrates, the relationship between knowledge of classroom language teaching and CALL should be considered tentative. However, surely there must be some principles of L2 teaching and learning that derive from and contribute toward both the traditional method and CALL (Chapelle).

Huang and Liu (2000) point out that the student-computer communication is relatively new to students. The computer software and students do not communicate with each other by " words." Instead, students need to learn another communication system. The computers communicate by means of graphic presentation, sound effect, and animated characters. Students have to learn how to communicate with the computer so that they know what move they should make next. Also, the communicative activities are different. In a traditional classroom, the teacher provides the topic-specific situation for students to make use of language as much as they can. Since the traditional classroom is far from any similarities to the real life situation, the teacher has to tell students to use their imagination. Innovation in language teaching and learning technology, especially those, like CALL, which offer challenges not only to the established roles of teachers and learners, the nature of materials and the organization of classrooms, but indeed to the language curriculum as a whole, need to be provided with an educational rationale. (Leech \& Candlin, 1986).

\subsection{Classification of CALL}

CALL has been classified from many perspectives. Tim Johns (1990) offers a lively description of four approaches to computer assisted language teaching, each associated with a metaphor.

Syringe: injecting the learner with knowledge

Gymnasium: reflected in words like "drill" and "exercise"

Bath: which gives us the expression "total immersion" as a description of learning

Test tube: sees the learner as somebody who can discover rules by examining evidence.

What is the classification of CALL from the learners' and teachers' perspectives.

\subsubsection{From the learners' perspective}

In 1977 a team of researchers at the University of East Anglia headed by Stephen Kemmis produced a report called "How Do Students Learn?" examining a large body of software in the sciences, geography and history. Kemmis's classification scheme divides the material into four classes that he called four paradigms: instructional, revelatory, conjectural, and emancipatory. I think this classification can be also used on CALL from students' perspective.

The instructional paradigm is essentially programmed learning. For this type of CALL, students are relatively passive when learning since everything is beforehand programmed. There are less two-way communications between learners and computer, and learners are navigated by the programs. This CALL is almost the same as tutor from teachers' perspective.

The revelatory paradigm includes activities where things are revealed gradually to learners through simulation or some kind of problem-solving activity. I would include text reconstruction under this heading.

The conjectural paradigm covers activities in which the learner explores in an unstructured way, tries to teach the computer, or writes programs to solve a problem. This type of CALL requires the learners to have some basic knowledge of computer technology. It is quite like a tutee from teachers' perspective.

The emancipatory paradigm refers to the use of computers purely as tools, e.g. for word-processing or on-line dictionary use.

\subsubsection{From the teachers' perspective}

Littlewood (1981) sees the 'good teacher' as a knowledge source who presents the language material and offers explanations, leads practice, and finally tests. Traditionally, teachers choose also the method, offer opportunities for language use in relation to a particular topic or situation, control the syllabus (although in most cases this is dictated by the course book), and provide feedback e.g. through correction and testing. The introduction of computers in language teaching was initially expected to have an impact on the teacher's role, although this now seems likely to be a slow process.

From teacher's perspective, CALL can be classified as tutor, Socratic, tutee and tool. 
Tutor

The 'CALL as tutor' framework employs the computer programs as tutor of foreign language. In order for the computer to be a tutor of this matter, the computer would be programmed as an expert in language teaching. Like a traditional teacher, these programs could teach the students in that subject, evaluate the student's results, keep records of how the student is progressing, note the student's weaknesses and determine what exercise should be dealt with next. In theory, it sounds like an ideal situation and you might think that eventually computers will play a greater role in the classroom than the teacher. Two assumptions seem to be made for the tutor role. First, the teacher is not present, and second, that CALL work "is taking place in self-access mode outside the conventional classroom" (Levy, 1997).

\section{Socratic}

Socratic is a teaching method, which prefers teaching by asking instead of by telling. Socratic method requires calling on students without giving them prior notice. The Socratic method encourages participants to reflect and think independently and critically. CALL programs are authored by means of question-and-answer drill. It is just like dialogue drill in language teaching classroom.

Tutee

CALL as tutee places the emphasis on the learners being firmly in control, teaching the computer what to do rather than vice versa. In order to achieve this, the learner must have knowledge of an artificial language such as Visual Basic. To carry out a function the learner must enter a series of instructions in the machine.

Tool

CALL can be presented as a tool. In this case, CALL is just like a learning tool and the learner is not controlled by any programs. This is a totally open teaching method. There are many CALL tools, and in this part, I will just look at four key CALL tools: video conferencing, email, CD, and WWW.

Video conferencing, in which participants can see each other and communicate with each other via TV cameras and a screen, is a typical synchronous activity: it is akin to a traditional classroom. Chen (1994) describes the stages and actions of video conferencing shown in table 2 ..

Video conferencing saves time. People in different places can communicate at the same time. But at present, this technology still has some disadvantages. First, this technology has not popularized. Only few organizations have this system. Second, the picture is not as clear as people expect. Further, due to the low speed of the net, sometimes the sound and picture can not be well matched.

E-mail is getting to be more and more common. E-mail shares the advantage with the telephone that it is quick, in that it is possible to get an almost immediate answer, but it is much cheaper than long-distance telephoning. An e-mail message can be delivered almost anywhere in the world in just a few minutes, and if the other person is at their computer, we can get a reply very quickly. Large amounts of information can easily be sent by e-mail. We can, for example, send an entire academic paper--or even an entire book, if we want to, though we may have to divide it up into several messages.

However, email has disadvantages as well. While in theory, we can get a reply to an e-mail message very quickly, this might not always happen in practice. Some people do not check their e-mail messages regularly, for example. If you do not receive an answer quickly, you will not know why. The message may not have been delivered, the other person may not have checked their e-mail, they may have decided not to answer, or it may take some time to get the information you want.

If you have an Internet connection and a program to read Web files (a "browser"), you can take advantage of this useful resource.

There are three main ways in which the Web can assist with teaching languages:

- Find resources which you can download / print and use with a class.

- Allow your students to find resources on their own or use specific materials on-line.

- Create your own Web pages / let your students create their own Web pages.

There are, of course, advantages and disadvantages to using the Web in all the above situations, but most of those who have taken the plunge have not regretted it. Clare Bradin, in her article "The Dark Side of the Web" (Bradin 1997), lists the following advantages and disadvantages to using the Web with students.

Advantages:

- provides students with authentic language

- up-to-the-minute information 
- real communication

- motivating

- relevant to content-based instruction

Disadvantages:

- World Wide Wait: Big files can be slow to load into memory. The wait time can be maddening for your students.

- Information glut: There is so much information that it may be too time-consuming to find the "good stuff." Even with search engines, it's still hard to find what you want.

- Some web sites are thin in substance.

- Users can get lost in cyberspace.

CD-ROM is a Compact Disk, which can contain amounts of information and is accessible in CD-ROM drive. It is suited for storing information requiring a huge amount of memory. CD-ROM is a good tool for language learning. It can be offline or online. Real English is a CD-ROM series for beginning level English learners. It would be appropriately used either as part of a traditional English course or for self-study. Lively videos, man/woman on the street interviews, the opportunity to practice speaking and listening, and a variety of good listening activities make the Real English CD-ROM series an excellent resource. The basic features are video, pronunciation, listening, watching, grammar presentation, voice recognition, etc.The relationship between teaching approach and CALL types can be illustrated by the table 3 .

\section{Conclusion}

From the above discussion, we have learned that both traditional language learning and CALL have advantages and disadvantages. But using computers to assist language learning and teaching is the certainty and necessity of technological development. CALL has widely adopted around the world and it will become the major approach of language learning and teaching. However, CALL has not yet well been developed in colleges and University in China. Since CALL is not always better than traditional language learning and teaching method. How to develop CALL in colleges and university for English language learning and teaching to meet the needs of teachers and students? This question still needs further study. But what is important in our university system is that CALL design and implementation should match the users' needs, since CALL is not always better than traditional language learning and teaching method. So before designing the CALL system, we should have an investigation to the users including students and staff.

\section{Appendix}

CALL: Computer Assisted Language Learning

WWW :The World Wide Web

CD-ROM : Compact-Disc-Read-Only-Memory.

L2: Second language

CAI: Computer Aid Instruction

\section{References}

Bradin, C. (1997). CALL issues: Instructional aspects of software evaluation. In J. Egbert \& E. Hanson-Smith (Eds.), CALL Environments: Research, Practice, and Critical Issues (pp. 159-175). Alexandria, VA: TESOL Publications.

Cameron, K. (1989). Computer-Assisted Language Learning: Oxford: Oxford University.

Chapelle, C. (2001). Computer Applications in Second Language Acquisition: Foundations for Teaching, Testing, and Research. Cambridge, UK: Cambridge University Press.

Chen YC \& Jeng SW,(1994). Two-Layer Coding for ATM-Based Video Transmission Systems, Science Publishers, pp.737-746.

Jones G. (1986). Computer simulations in language teaching.

Johns, T. \& King, P. (1991). Classroom Concordancing. Special Issue of ELR Journal 4, University of Birmingham: Centre for English Language Studies.

Littlewood, W. (1981). Communicative Language Teaching. New York: Cambridge University Press.

Liu, Y. (2000). The effects of nonverbal cues on impression formation in computer-mediated communication: An exploratory study. Dissertation Abstracts International, 61(4).

Levy, Michael. (1997). Computer-assisted language learning: Context and conceptualization. New York: Oxford 
University Press. 298 pages.

http://www.extreme-learning.com/call accessed on July 15, 2001.

Table 1. Advantages and disadvantages of CALL

\begin{tabular}{|c|c|}
\hline Advantages & Disadvantages \\
\hline $\begin{array}{l}\text { Learning Advantages: } \\
\text { - } \quad \text { Self-paced or learner-centered. } \\
\text { - } \text { An active process. } \\
\text { - } \quad \text { Available to language learner when he wants it. } \\
\text { - CALL material is consistent within individual } \\
\text { courses. } \\
\text { Teaching Advantages: } \\
\text { - Getting to know the students' individual } \\
\text { problems and successes with the learning material. } \\
\text { - Working with a group of disciplined students. } \\
\text { - Focusing on the important or more difficult } \\
\text { material during class time or tutoring sessions. }\end{array}$ & $\begin{array}{l}\text { - Quite a few students feel they learn better } \\
\text { when guided step by step through a concept. The } \\
\text { student must be motivated and disciplined to } \\
\text { complete a learning program on his own, without a } \\
\text { teacher looking over his shoulder. } \\
\text { - A good CALL program, as with all CBE } \\
\text { programs, is very expensive to develop. } \\
\text { - Development requires teacher input, but, a } \\
\text { great number of teachers see programs such as } \\
\text { CALL as replacement. } \\
\text { - There is also a lack of suitable software } \\
\text { available for CALL today. }\end{array}$ \\
\hline
\end{tabular}

Table 2. Stages and actions of video conferencing

\begin{tabular}{|l|l|}
\hline Stage & Actions \\
\hline \multirow{3}{*}{ Pre-meeting } & $\bullet \quad$ Develop statement of problem and goals \\
& $\bullet \quad$ Decide on idea generation and consensus-building approach (brainstorm, delphi) \\
& $\bullet \quad$ Pevelop background \& support materials \\
\hline \multirow{3}{*}{ Meeting } & $\bullet \quad$ In plenary state goals, give material, explain approach \\
& $-\quad$ Elicit ideas and capture them \\
& $\bullet \quad$ Organize ideas and assess them \\
\hline Post-meeting & Review and cycle again \\
\hline
\end{tabular}

Table 3. Teaching approaches and CALL classification

\begin{tabular}{|l|l|l|l|l|}
\hline Teaching approaches & Closed & Drill & Discovery & Open \\
\hline $\begin{array}{l}\text { CALL from teachers' } \\
\text { perspective }\end{array}$ & Tutor & Socratic & Tutee & Tool \\
\hline $\begin{array}{l}\text { CALL from students' } \\
\text { perspective }\end{array}$ & Instructional & Revelatory & Conjectural & Emancipatory \\
\hline
\end{tabular}


Knowledge about

classroom teaching
Knowledge about

CALL

a. The tentative connection between classroom teaching and CALL

\begin{tabular}{|c|c|}
\hline $\begin{array}{c}\text { Knowledge about } \\
\text { classroom teaching }\end{array}$ & $\begin{array}{c}\text { Principles of good language } \\
\text { learning tasks }\end{array}$ \\
\hline
\end{tabular}

b. General principles connecting knowledge of classroom teaching and CALL

Figure 1. The relationship between classroom L2 teaching and CALL 